\title{
EDUCAÇÃO DE JOVENS E ADULTOS: as reivindicações populares por uma educação que possibilite a diminuição das distâncias sociais
}

\author{
Rogério Feitosa Barros ${ }^{1}$ \\ Rosângela de Fátima Cavalcante França² \\ Wendell Fiori de Faria ${ }^{3}$
}

\section{RESUMO}

Avanços impulsionados pelas lutas populares sugerem a necessidade de um debate em prol de uma formação que atenda à realidade dos alunos da Educação de Jovens e Adultos (EJA). Nesse contexto, este estudo teve por objetivo analisar como a formação dos alunos da EJA pode contribuir para a sua participação ativa nas questões sociais. Trata-se de uma pesquisa descritiva, de abordagem qualitativa, realizada no período de 2018 a 2019. Em relação ao tratamento dos dados foi utilizada a análise de conteúdo, dessa forma foram criadas categorias a priori e a posteriori em consonância com os objetivos da pesquisa e de acordo com a similaridade das respostas dos participantes. Os sujeitos da pesquisa foram alunos e professores da EJA, de escolas da Rede Municipal de Educação de Porto Velho-RO. Os resultados evidenciaram que o conhecimento sistematizado poderá proporcionar aos alunos da EJA a participação ativa em situações que envolvam seus direitos e deveres. Nessa perspectiva, conclui-se que é necessário que a formação destes se efetive com a problematização dos conteúdos, alinhada à realidade sociocultural real dos alunos e com a melhoria das condições materiais de trabalho nessa modalidade de ensino.

Palavras-chave: Educação de Jovens e Adultos. Educação Popular. Direitos Humanos.

\footnotetext{
1 Mestre em Educação pela Universidade Federal de Rondônia (UNIR), Porto Velho-RO, Brasil. Orcid iD: https://orcid.org/0000-0002-9005-6010.E-mail: educadorbarros@gmail.com

2 Doutora em Educação pela Universidade Estadual Paulista (UNESP). Professora do Departamento de Educação (DECED) e no Programa de Pós-Graduação Stricto Sensu, Mestrado Acadêmico em Educação (PPGE) da Universidade Federal de Rondônia (UNIR), Porto Velho-RO, Brasil. Orcid iD: https://orcid.org/0000-0003-2301-7000. E-mail: brosangela@gmail.com

3 Pós-Doutor em Educação pela Universidade de São Paulo (FEUSP). Professor do Departamento de Educação (DECED) e no Programa de Pós-Graduação Strictu Sensu, Mestrado Acadêmico em Educação (PPGE) da Universidade Federal de Rondônia (UNIR), Porto Velho-RO, Brasil. Orcid iD: https://orcid.org/0000-0003-4195-1876. E-mail: professorfiori@gmail.com
} 


\title{
YOUTH AND ADULT EDUCATION: popular claims for education that decreases
}

\author{
social distances
}

\begin{abstract}
Advances driven by popular demands supports the stance for a debate in favor of training that meets the requirements of students of Youth and Adult Education (EJA). In this context, this study aims to analyze how the training of EJA students can contribute to their active participation in social issues. It is a descriptive research, with a qualitative approach, carried out from 2018 to 2019. Regarding data treatment, content analysis was used, thus creating categories a priori and a posteriori in line with the objectives of the research and according to the similarity of the participants' responses. The subjects of the research were students and teachers of EJA, from schools of the Municipal Education Network of Porto Velho - RO. The results showed that systematized knowledge can provide EJA students with active participation in situations involving their rights and duties. From this perspective, it is concluded that it is necessary that their training is effective with the problematization of the contents, aligned with the real sociocultural reality of the students and with the improvement of the material working conditions in this modality of teaching.
\end{abstract}

Keywords: Youth and Adult Education. Popular Education. Human rights.

\section{EDUCACIÓN DE JÓVENES Y ADULTOS: demandas populares de una educación que permita reducir las distancias sociales}

\section{RESUMEN}

Los avances conquistado por las luchas populares sugieren la necesidad de un debate em relación a una formación que responda a la realidad de los estudiantes de Educación de Jóvenes y Adultos (EJA). En este contexto, este estudio tuvo como objetivo analizar cómo la formación de los estudiantes de EJA puede contribuir para su participación activa en temas sociales. Se trata de una investigación descriptiva, con enfoque cualitativo, realizada de 2018 a 2019. En cuanto al tratamiento de los datos, se utilizó el análisis de contenido, creando categorías a priori y a posteriori de acuerdo con los objetivos de la investigación y según la proximidad de las respuestas de los participantes. Los sujetos de la investigación fueron estudiantes y profesores de EJA de escuelas de la Red Municipal de Educación de Porto VelhoRO. Los resultados mostraron que el conocimiento sistematizado puede brindar a los estudiantes de EJA una participación activa en situaciones que involucran sus derechos y deberes. Desde esta perspectiva, se concluye que es necesario que la formación se efective junto a la problematización de los contenidos, aproximada a la realidad sociocultural de los alumnos y que vise la mejora de las condiciones materiales de trabajo en esta modalidad de enseñanza. 
Palabras clave: Educación de Jóvenes y Adultos. Educación Popular. Derechos humanos.

\section{INTRODUÇÃO}

Os avanços que sucederam no campo educacional direcionado às classes subalternas da sociedade são uma realidade estabelecida ao longo de décadas de lutas e reivindicações populares.

Historicamente, a organização de grupos com interesses comuns, em favor da construção de uma sociedade mais igualitária, contribuiu para impulsionar a elaboração de leis que delimitam direitos e garantias sociais. Fato que não pode ser negado é a interferência do poder hegemônico na preparação dessas leis, que carregam em seus textos, também, as demandas de uma minoria detentora do poder econômico. Dessa forma, a legislação educacional construída historicamente articula interesses tanto das classes populares menos favorecidas, quanto dos interesses hegemônicos das classes dominantes.

Vale considerarmos que as transformações sociais nunca deixam de acontecer. Nesse sentido, a sociedade contemporânea passa por um momento histórico de aceleração na produção de novos conhecimentos, visto que os avanços ligados às novas tecnologias da comunicação e informação pressionam os cidadãos a uma constante busca por formação.

Isto posto, ressaltamos a necessidade de um olhar diferenciado para a Educação de Jovens e Adultos (EJA). Os alunos que compõem essa modalidade educativa são cidadãos em idade economicamente ativa em busca do conhecimento formal pelos mais variados motivos. Historicamente, são pessoas que em grande parte, tiveram negadas oportunidades de uma vida mais igualitária e não puderam estudar na idade considerada adequada.

É nesse contexto que reforçamos a relevância social desta pesquisa, na medida em que buscamos discutir a EJA na perspectiva de formação para a cidadania. Dessa forma, enfatizamos, também, a relevância científica da pesquisa, pois a EJA não pode ser alijada das discussões 
educacionais no campo acadêmico que ressaltam o direito humano e universal à educação de boa qualidade.

Para delimitar nossa pesquisa, formulamos o seguinte problema a ser respondido: Em que medida a formação dos alunos da EJA pode contribuir para a participação ativa nas questões sociais?

Com o propósito de responder à questão norteadora da pesquisa, estabelecemos o seguinte objetivo geral: analisar como a formação dos alunos da EJA pode contribuir para a participação ativa nas questões sociais.

Para o desdobramento do objetivo geral desta pesquisa, trabalhamos com os seguintes objetivos específicos:

a) Identificar quais requisitos o professor leva em consideração para o desenvolvimento do seu trabalho em sala de aula, tendo em vista a superação das dificuldades e necessidades dos alunos da EJA;

b) Verificar como os alunos da EJA percebem sua formação escolar como um mecanismo de participação ativa nas questões sociais.

Para a materialização deste estudo, realizamos a pesquisa do tipo descritiva (GIL, 2002), de abordagem qualitativa (BOGDAN e BIKLEN, 1994), a interpretação dos dados foi realizada por meio da análise de conteúdo (BARDIN, 2016). Foi desenvolvida em duas fases: a bibliográfica e a empírica. Os dados foram obtidos por meio de questionários. Foram sujeitos deste estudo cinco professores e 24 alunos de seis escolas de Educação de Jovens e Adultos do município de Porto Velho-RO.

Para a produção deste estudo, desenhamos a seguinte estrutura: introdução, aporte teórico, metodologia, análise e discussões e considerações finais. Dessa forma, na introdução é feita a contextualização geral do trabalho. O aporte teórico traz autores que tenham pertinência e consistência, na medida em que são pesquisadores com vastas publicações sobre a temática estudada, dentre os quais podemos destacar: Freire (2011), Gadotti (2011) e Arroyo (2011), que discutem conceitos e características da educação popular; Capucho (2012), Gadotti (2013) e Brandão (2016), que tratam da educação em direitos humanos. Em relação à metodologia nos 
aportamos em Gil (2008), Bogdan e Biklen (1994) e Bardin (2016). Quanto à análise e discussões, seguimos procedimentos que nos permitiram organizar os dados, interpretá-los e analisá-los à luz de um referencial teórico pertinente à temática investigada. Por fim nas considerações finais são retomados os principais aspectos da análise dos dados, além disso, por meio dos resultados é apresentada a resposta à questão norteadora da pesquisa.

Em decorrência do alcance dos objetivos, a relevância deste estudo consiste na apresentação de indicadores sobre as características que permeiam a formação no âmbito da EJA. Os resultados evidenciaram que o conhecimento sistematizado poderá proporcionar aos alunos da EJA a participação ativa em situações que envolvam seus direitos e deveres, o que nos leva a concluir que a formação destes se efetive com a problematização dos conteúdos, alinhada à realidade sociocultural real dos alunos e com a melhoria das condições materiais de trabalho nessa modalidade de ensino.

\section{EDUCAÇÃO DE JOVENS E ADULTOS: múltiplos aspectos}

\section{A Educação Popular}

Uma das formas de se pensar a EJA como um caminho de desenvolvimento das classes menos favorecidas é a que conduz aos princípios da Educação Popular. Nesse sentido, buscamos explanar alguns caminhos e possibilidades, com base nos estudos de alguns autores.

Gadotti $(2011$, p. 36) considera que:

A educação popular, como uma concepção geral da educação, via de regra, se opõe à educação de adultos impulsionada pela educação estatal e tem ocupado os espaços que a educação de adultos oficial não levou muito a sério.

Pensar a educação popular possibilita discutir de que forma a educação ofertada pelo poder público se distancia das demandas das classes populares mais baixas, constituídas de ampla diversidade. 
De acordo com Freire (2011, p. 22), "Educadores e grupos populares descobriram que Educação Popular é, sobretudo, o processo permanente de refletir a militância; refletir, portanto, a sua capacidade de mobilizar em direção a objetivos próprios".

Sendo uma educação voltada às classes e grupos desfavorecidos, a Educação Popular visa à conscientização por intermédio de diálogos que coloquem em debate as necessidades, das mais básicas às mais complexas, desses grupos que, historicamente, foram excluídos das decisões que afetam o seu meio social e suas próprias vidas.

Em termos materiais, Arroyo $(2011$, p. 68) faz referência a um fenômeno legítimo, recorrente em grupos populares que lutam por uma mesma causa:

[...] não só há no campo uma dinâmica social, ou movimentos sociais no campo, também há um movimento pedagógico. Procuro estar atento por onde é que neste país está acontecendo a renovação educativa e observo que está acontecendo nos movimentos sociais e nos governos populares.

O pesquisador contextualiza uma educação que foge ao modelo padronizado pelo sistema formal, uma pedagogia que olhe para as reivindicações das classes populares e tenha como temáticas de discussão a realidade vivida pelos militantes que reivindicam pelos seus direitos. A origem dessa pedagogia vivente no campo remete, historicamente, aos meios de lutas populares.

Sobre essa relação entre educação e movimentos populares, Freire (2011, p. 23) esclarece que:

Esse movimento de superação do senso comum implica uma diferente compreensão da História. Implica entendê-la e vivê-la, sobretudo vivê-la, como tempo de possibilidade, o que significa a recusa a qualquer explicação determinista, fatalista da História.

Dessa forma, o autor destaca o enfrentamento a um poder hegemônico que articula a estrutura do Estado para manter o modelo social. Assim, sobrepujar ou, pelo menos impactar de forma a diminuir as 
distâncias entre as camadas sociais, é possível, mediante uma educação emancipadora, que priorize a reflexão sobre a realidade.

Nessa linha, Gadotti (2011, p. 36-37) argumenta que:

Um dos princípios originários da educação popular tem sido a criação de uma nova epistemologia baseada no profundo respeito pelo senso comum que trazem os setores populares em sua prática cotidiana, problematizando esse senso comum, tratando de descobrir a teoria presente na prática popular, teoria não conhecida pelo povo [...].

Com a interferência da ação pedagógica adequada é possivel e necessário aproveitar o conhecimento popular com vista a qualificá-lo. Isso se concretiza dando-se relevância às histórias de vida dos sujeitos e ao que foi apreendido durante esse percurso, isto é, articulando-se todo esse conhecimento popular ao científico.

Freire (2011, p. 23) ratifica essa reflexão, afirmando que: "Assim compreendida e posta em prática, a Educação Popular pode ser socialmente percebida como facilitadora da compreensão científica que grupos e movimentos podem e devem ter acerca de suas experiências".

Dessa maneira, o processo de ensino e aprendizagem desenvolvido junto aos alunos jovens e adultos, na escola ou em outros espaços que promovam ações educativas, tem como possibilidade a aplicação dos princípios da Educação Popular, já que a EJA é constituída de alunos das mais baixas classes sociais, pessoas que tiveram o mínimo de boas oportunidades, mas que trazem consigo as marcas de experiências vividas, seus sonhos, esperanças e objetivos.

Ainda nessa esteira de pensamento, Freire (2011, p. 22) nos explica que:

Dessa forma são tão importantes para a formação dos grupos populares certos conteúdos que o educador lhes deve ensinar, quanto a análise que eles façam de sua realidade concreta. E, ao fazê-lo, devem ir, com a indispensável ajuda do educador, superando o seu saber anterior, de pura experiência, feito, por um saber mais crítico, menos ingênuo. O senso comum só se supera a partir dele [...]. 
Esse modo de lidar com o processo de ensino exige, por parte dos professores e professoras da EJA, refletir sua ação educativa. Partindo desse pressuposto, é importante lidar com as peculiaridades dos alunos, conhecêlos e considerar que, para além de receptores de informação, são sujeitos que buscam a superação do seu conhecimento.

Como explica Freire $(2011$, p. 21$)$ :

Não é possível a educadoras e educadores pensar apenas os procedimentos didáticos e os conteúdos a serem ensinados aos grupos populares. Os próprios conteúdos a serem ensinados não podem ser totalmente estranhos àquela cotidianidade.

Mesmo com direcionamento construído a partir de referenciais determinados pelos sistemas educacionais, os professores podem, diante de sua autonomia, adequar sua prática à realidade concreta dos seus alunos. Considerando o aluno como centro do processo educativo, os educadores podem abrir caminhos para educação de boa qualidade e que reflita a vontade dos sujeitos que estão sob sua orientação.

Gadotti $(2011$, p. 39) considera que:

Ler sobre a educação de adultos não é suficiente. É preciso entender, conhecer profundamente, pelo contato direto, a lógica do conhecimento popular, sua estrutura de pensamento, em função da qual a alfabetização ou a aquisição de novos conhecimentos têm sentido.

Entender como acontece a vida cotidiana dos alunos, suas vivências no trabalho, em seus lares e interações corriqueiras são informações que podem ser utilizadas para problematizar os conteúdos a serem apresentados pelo professor. Uma educação popular dá significado ao que está sendo posto para superação.

Freire $(2011$, p. 23) destaca que:

Respeitando os sonhos, as frustrações, as dúvidas, os medos, os desejos dos educandos, crianças, jovens ou adultos, os educadores e educadoras populares têm neles um ponto de partida para a sua ação. Insista-se, um ponto de partida e não de chegada. 
Colocando-se os alunos no centro do processo e respeitando sua condição humana, constituída de múltiplas dimensões, surge uma infinidade de oportunidades educativas a serem exploradas.

Assim, a educação popular é dedicada a pessoas que, historicamente, tiveram seus direitos e garantias negados ou, no mínimo, se apresentaram de forma fragilizada.

\section{A Educação em Direitos Humanos}

Ao tratar da Educação Popular, direcionada às pessoas menos favorecidas, consideramos importante, também, tecer uma reflexão a respeito da Educação em Direitos Humanos, haja vista a diversidade cultural, étnica e de gênero existente em nosso país, além da marcante divisão de classes.

Conforme a UNESCO (1998, p. 04):

A instrução será orientada no sentido do pleno desenvolvimento da personalidade humana e do fortalecimento do respeito pelos direitos humanos e pelas liberdades fundamentais. A instrução promoverá a compreensão, a tolerância e a amizade entre todas as nações e grupos raciais ou religiosos, e coadjuvará as atividades das Nações Unidas em prol da manutenção da paz.

A Declaração Universal dos Direitos Humanos traz em seu texto princípios de direitos e garantias que devem alcançar a todos. Nesse sentido, a educação tem o papel de preservar a humanidade entre os povos, promovendo a reflexão sobre a individualidade das pessoas e as características da natureza humana.

A Secretaria de Direitos Humanos da Presidência da República considera que:

O Brasil é um país onde os problemas sociais vêm sendo redimensionados através de programas e incentivos de políticas públicas de inclusão e reparo às violações dos direitos humanos. Ainda o preconceito e as disparidades sociais contribuem para 0 declínio do cenário humanístico, cultural, político e econômico. Os direitos humanos podem mudar essa realidade e a educação é o principal viés para essa transformação, por meio da dignidade da pessoa humana (BRASIL, 2013, p. 43). 
O texto revela que as marcas da intolerância vão além da parte diretamente ofendida e isso se propaga no meio social, atingindo mesmo quem pensa estar imune a qualquer interferência. As consequências de ações que reforçam as desigualdades são prejudiciais a todos os setores que compõem uma comunidade.

A educação, entendida como uma das formas de superação desses problemas sociais, deve atingir a todos, inclusive àqueles que não tiveram oportunidade de acesso.

A esse respeito, Capucho (2012, p. 22) assim argumenta:

Nessa direção, a luta histórica pela igualdade do direito a Educação e o enfrentamento às múltiplas formas de exclusão social resultaram na garantia da Educação de Jovens e Adultos como modalidade da Educação Básica.

Conforme discute a pesquisadora, a EJA se afirma na busca histórica das camadas populares pelo acesso ao conhecimento e pelo nivelamento das oportunidades com o objetivo de se alcançar uma vida digna.

Gadotti (2013, p. 14), por sua vez, compreende que:

A Educação de Adultos deve ser também uma educação em direitos humanos. Para isso, é fundamental que os conteúdos, os materiais e as metodologias utilizadas levem em conta esses direitos, e os programas propiciem um ambiente capaz de vivenciá-los.

Os direitos humanos estão presentes na vida e nas determinações legais. Para fazer valer esses direitos, seu conhecimento deve ser apresentado aos alunos. A EJA, frequentada por jovens e adultos de baixas condições de vida, necessita que esses alunos e alunas tenham práticas educativas que Ihes possibilitem atuar na busca pela materialização dos seus direitos e garantias legais, muitas vezes negados.

No entanto, conforme destaca Capucho (2012, p. 26), convém ressaltar que:

A difícil conciliação entre o proclamado e o efetivado revela a impossibilidade de conciliação entre a igualdade formal defendida pela democracia liberal e a desigualdade real engendrada pela 
divisão de classe advinda do capitalismo, pois os direitos sociais, dentre eles o direito à educação exige a redistribuição de bens, serviços e rendas na sociedade.

Considerando-se as palavras da autora, as conquistas legais advindas das reinvindicações populares não são garantia de igualdade de oportunidades, apenas sugerem melhoria nas condições de vida da população, tanto quanto o sistema econômico permita.

Capucho (2012, p. 28) ainda reflete que:

[...] apesar dos direitos educativos estarem proclamados na legislação nacional e constitucionalmente terem sido ampliados, os mecanismos de proteção da dignidade da pessoa humana, as violações dos direitos educativos são recorrentes na sociedade brasileira, demandando a formação de uma cultura de direitos a qual assegure o cumprimento da legislação vigente e favoreça a organização social em prol da conquista de novos direitos.

Dessa forma, mesmo sob um controle robusto do poder dominante, a legislação que promove maior liberdade à participação popular nas questões sociais avançou ao longo dos tempos. Assim, o papel da educação é ampliado ao mesmo tempo em que as leis são publicadas. Isso demanda a necessidade da ação educativa que forme um cidadão capaz de conhecer e fazer valer seus direitos e garantias.

Di Pierro, Joia e Ribeiro (2001, p. 74) ampliam esse pensamento, considerando que:

Cidadania é um conceito histórico, que comporta interpretações mutáveis e diversas. Os debates atuais sobre os objetivos da educação para a cidadania privilegiam a formação de sujeitos livres, autônomos, críticos, abertos à mudança, capazes de intervir em processos de produção cultural que tenham alcance político.

Nesse sentido, formar para a cidadania exige que o sistema educativo acompanhe as mudanças sociais, haja vista que há a necessidade de formação do sujeito que conheça a realidade ao seu redor e, ao mesmo tempo, se reconheça e interfira nessa realidade.

Brandão $(2016$, p. 167) ratifica esse pensamento, afirmando: 
Uma educação de vocação cidadã é uma educação política. É uma educação destinada a formar pessoas capazes de viverem a busca da realização plena de seus direitos humanos no mesmo processo de consciência crítica e de prática reflexiva com que se sentem convocadas ao dever cidadão de participarem de maneira ativa da construção dos mundos de sociedade e cultura de suas vidas cotidianas.

Desse modo, uma participação ativa no mundo demanda a relação entre o conhecimento adquirido por meio das experiências vividas e o conhecimento sistematizado e cientificamente formulado. E quando falamos desse tipo de conhecimento, pensamos em termos de qualidade e é nesse sentido que destacamos a interpretação de Jeffrey et al. $(2013$, p.) que ao fazerem uma leitura da Resolução CNE/CEB n 4 de 13 de julho de 2010, que define as Diretrizes Curriculares Nacionais Gerais para a Educação Básica, destacam o surgimento de um novo termo: a ideia da "qualidade social da educação" e sobre esta qualidade ressaltam:

A qualidade social da educação apresenta o conceito de uma oferta de educação escolar para todos, permeada por padrões de excelência e que seja capaz de atender os diferentes interesses da maioria da população. Traduz-se em inclusão social, onde todos os brasileiros se tornariam aptos à tomada de decisões, à conscientização, ao questionamento crítico e à problematização, capazes de buscar soluções coletivas possíveis e necessárias à resolução dos problemas de cada um e da comunidade onde viva e trabalha.

Para um melhor entendimento sobre esse tema, recorremos a Freire (2001, p. 31), segundo o qual "a conscientização não está baseada sobre a consciência, de um lado, e o mundo, de outro, por outra parte, não pretende uma separação. Ao contrário, está baseada na relação consciência-mundo".

Complementarmente, Capucho $(2012$, p. 37) assim se manifesta:

A formação para a cidadania vai além dos muros da escola. Ela é forjada no dia a dia das relações dos indivíduos e no conjunto das organizações da sociedade, pois a cidadania é uma situação política, social e econômica dependente de condições concretas. 
Por meio de uma educação que promova a reflexão sobre o que acontece na realidade cotidiana dos alunos e com o propósito de formar o sujeito que atue em prol do bem comum, a EJA poderá concretizar os princípios da Educação em Direitos Humanos.

De acordo com Gadotti (2013, p. 14):

\begin{abstract}
A Educação de Adultos é o espaço da diversidade e de múltiplas vivências, de relações intergeracionais, de diálogo entre saberes e culturas. Ao lado da diversidade está também a desigualdade que atinge a todos, sobretudo num país injusto como o nosso: negros, brancos, indígenas, amarelos, mestiços, homens, mulheres, jovens, adultos, idosos, quilombolas, ribeirinhos, pescadores, agricultores, pantaneiros, camponeses, sem-terra, sem teto, sem emprego...das periferias urbanas e dos campos. A diversidade pode ser considerada como uma grande riqueza, mas a desigualdade social e econômica é a nossa pobreza maior [grifos do autor].
\end{abstract}

Ao se considerar o universo heterogêneo composto pelos alunos e alunas da EJA, abre-se a possibilidade de reconhecimento dos múltiplos saberes e histórias de vida trazidas por esse público para o interior da sala de aula. Esse conhecimento popular demanda valorização, haja vista que pode ser compartilhado e passar por intervenção pedagógica que permita seu aprimoramento, valorizando-o ainda mais.

A respeito da Educação em Direitos Humanos, Capucho (2012, p. 40) explica que:

Ao versar sobre a Educação em Direitos Humanos em sua relevância no âmbito da Educação de Jovens e Adultos, se deve canalizar esforços para compreender o PNEDH [plano nacional de Educação em direitos Humanos] para além das letras, pois significa considerar uma proposta de EDH que não se restrinja ao enunciado, mas que promova inclusão, igualdade, e partilha da riqueza.

Os princípios da Educação em Direitos Humanos estão intrinsecamente relacionados às necessidades da Educação de Jovens e Adultos. Os alunos dessa modalidade possuem características diversas que acabam convergindo, em muitos casos, para a necessidade da participação efetiva nas decisões coletivas de suas comunidades. Dessa forma, é papel da escola de EJA reunir esforços para oportunizar que os educandos tenham 
acesso ao conhecimento teórico e prático das garantias legais que todo ser humano deve compartilhar.

\section{METODOLOGIA}

Esta pesquisa é do tipo descritiva, a qual está alinhada aos objetivos pretendidos, dessa forma, descreve elementos passíveis de serem investigados indicando as possibilidades nos mais variados fenômenos que envolvem, principalmente, os sujeitos sociais (GIL, 2008).

Considerando o conhecimento da realidade por meio dos sujeitos que a constituem e confrontá-la com a teoria levantada, entendemos que, neste processo, a abordagem qualitativa possa dar mais liberdade ao desenvolvimento do trabalho (BOGDAN; BIKLEN, 1994).

Em relação ao tratamento dos dados, utilizamos a análise de conteúdo, assim, buscamos, por meio de nossas percepções, aproximar três fatores que consideramos cruciais: as respostas dos participantes, a revisão literária e os objetivos da pesquisa (BARDIN, 2016).

A presente pesquisa tem como sujeitos participantes cinco professores e 24 alunos da modalidade de EJA, da rede municipal de educação da cidade de Porto Velho-RO. Com vistas à concretização das atividades pertinentes, este estudo se desenvolveu seguindo os seguintes procedimentos: 1. Definição do objeto de estudo; 2. Elaboração da questão problematizadora; 3. Elaboração dos objetivos; 4. Leitura de novos referenciais teóricos para aprofundamento da temática investigada; 5. Fichamento dos textos pertinentes à temática da pesquisa; 6. Produção do quadro teórico; 7. Definição dos sujeitos da pesquisa; 8. Elaboração do roteiro com datas, horários, locais e sujeitos, para a pesquisa empírica; 9. Convite via documentos de apresentação e autorização, aos sujeitos deste estudo, buscando o aceite quanto à participação no mesmo; 10. Aplicação dos questionários; 11. Organização dos dados da pesquisa; 12. Análise dos dados obtidos por meio dos questionários respondidos. 


\section{A EDUCAÇÃO DE JOVENS E ADULTOS: percepções para essa modalidade em uma perspectiva de formação para a cidadania}

Nesta seção, apresentamos o resultado do trabalho que realizamos com a obtenção dos dados coletados em nosso estudo empírico. Seguimos procedimentos que nos permitiram organizar os dados, interpretá-los e analisá-los à luz de um referencial teórico pertinente à temática investigada.

A análise possui dois momentos. No primeiro momento, temos o questionamento aos professores. Quanto ao segundo momento, trabalhamos com os dados obtidos com os alunos. Assim apresentamos a análise, a qual constitui o cerne desta pesquisa.

\section{A fala dos professores}

Para o primeiro momento, foram criadas categorias a posteriori, com base nos critérios de similaridade e frequência das respostas apresentadas pelos professores participantes da pesquisa. Na Figura 1, demonstramos as categorias de análise utilizadas:

Quadro 1 - Primeiro momento: Quadro das categorias criadas em consonância com as respostas dos professores

\begin{tabular}{|l|l|}
\hline \multicolumn{2}{|c|}{ Categorias a posteriori } \\
\hline Categoria I & $\begin{array}{l}\text { Requisitos voltados para a valorização dos saberes e } \\
\text { condições de oportunidades }\end{array}$ \\
\hline Categoria II & Mecanismos que proporcionam autonomia do aluno \\
\hline
\end{tabular}

Fonte: Elaborado pelo pesquisador, 2019.

CATEGORIA I: Requisitos voltados para a valorização dos saberes e condições de oportunidades.

Tendo em vista as funções previstas em lei para a Educação de Jovens e Adultos, quais os requisitos que você leva em consideração para o desenvolvimento do seu trabalho em sala de aula? 
Possibilitar a todos as mesmas oportunidades e compartilhamento de aprendizagem. Provocar nele o exercício de experimentação de novas aprendizagens (P1).

Em primeiro lugar valorizar o conhecimento do aluno, trazer os temas ou conteúdos a serem desenvolvidos para um contexto que eles já conheçam, utilizar de palavras do cotidiano na intenção de que faça sentido (P2).

Aparelhamento eficaz dos educandos, educadores e escola com os livros eficazes, condições decentes de trabalho e materiais interativos (P3).

A empatia, solidariedade com os alunos da EJA, a valorização dos saberes adquiridos em suas vivências etc. (P4).

Trabalhar a partir do conhecimento de cada um, através de suas experiências e respeitar as dificuldades do aluno (P5).

Em relação às respostas dos participantes P2, P4 e P5, percebemos que há convergência quanto ao entendimento de que os alunos da EJA possuem um conhecimento adquirido por meio de suas experiências.

Ao ressaltarem que consideram os conhecimentos prévios dos alunos, os professores denotam que há valorização desses saberes e isso poderá ser um indicador para que o professor trabalhe de forma concreta, voltado às necessidades e possibilidades da turma. Tal entendimento encontra fundamentação no Parecer 11/2000, que assim dispõe:

[...] a heterogeneidade do público da EJA merece consideração cuidadosa. A ela se dirigem adolescentes, jovens e adultos, com suas múltiplas experiências de trabalho, de vida e de situação social, aí compreendidas as práticas culturais e valores já constituídos (BRASIL, 2000, p. 61).

Nessa linha, o Parecer ratifica o que foi dito pelos participantes, considerando os saberes que os alunos trazem consigo para o interior da sala de aula como recurso a ser utilizado no processo educativo.

Para aprofundar a discussão, nos ancoramos em Freire (2013, p. 31), visto que:

[...] pensar certo coloca ao professor ou, mais amplamente, à escola, o dever de não só respeitar os saberes com que os educandos, sobretudo os das classes populares, chegam a ela - saberes socialmente construídos na prática comunitária -, mas também, [...] 
discutir com os alunos a razão de ser de alguns desses saberes em relação com o ensino dos conteúdos.

Dessa forma, o professor não deve ignorar os saberes dos alunos, adquiridos por sua vivência, mas tomá-los como ponto de partida para a problematização e construção de novos conhecimentos.

Nessa perspectiva, a valorização dos conhecimentos prévios dos alunos contribui para qualificar o ensino, abrindo possibilidades para estratégias didáticas que aliem os saberes das experiências de mundo com os conhecimentos sistematizados. Dessa maneira, pode-se caminhar em direção à construção do conhecimento que sirva para o entendimento e resolução das mais variadas situações que se apresentam na vida cotidiana.

Também sobressaem, nas falas dos participantes, a intenção em proporcionar igualdade de oportunidades quanto aos conhecimentos, por parte dos alunos, seja pelo trabalho docente, como destaca P1, ou por reinvindicações relacionadas a condições materiais, como descrito por P3. Nesse aspecto, o Parecer 11/2000, enfatiza:

Muitos alunos da EJA têm origens em quadros de desfavorecimento social e suas experiências familiares e sociais divergem, por vezes, das expectativas, conhecimentos e aptidões que muitos docentes possuem com relação a estes estudantes. Identificar, conhecer, distinguir e valorizar tal quadro é princípio metodológico a fim de se produzir uma atuação pedagógica capaz de produzir soluções justas, equânimes e eficazes (BRASIL, 2000, p. 61).

Ao destacar a questão do desfavorecimento social e da importância docente em valorizar o meio onde se vive e as relações dos alunos, o documento demonstra que esta modalidade educativa requer esforço do educador, no sentido de diagnosticar as necessidades de sua turma, o que dificulta ainda mais se olharmos para o universo heterogêneo que compõe a sala de aula da EJA.

Isso posto, ampliamos o olhar sobre as desigualdades que caracterizam os alunos da EJA, recorrendo ao pensamento de Rummert (2006, p. 123), que assim se posiciona: 
[...] a Educação de Jovens e Adultos trabalhadores, compreendida como o conjunto de processos educativos destinados àqueles que vivenciam diversas interdições que as profundas assimetrias de poder inerentes à sociedade capitalista impõem à classe trabalhadora, no que se refere ao acesso pleno ao conhecimento. Designamos, assim, como classe trabalhadora, a imensa maioria da população brasileira que vivencia situações cada vez mais precárias de produção da existência, dependendo para viver, ou, no mais das vezes, sobreviver, da venda, em condições cada vez mais adversas, e perversas, de sua força de trabalho.

Ao ratificar as desigualdades sociais presentes na sociedade capitalista, Rummert (2006) aponta o desfavorecimento das classes subalternas até mesmo sobre o direito básico e universal ao conhecimento produzido e sistematizado pelo homem. Essas diferenças de classe acarretam condicionante que pode interferir na desvalorização da ação humana sobre os meios de produção: quanto mais baixa a classe, aumenta a possibilidade de menor conhecimento escolar, menores os salários e piores as condições de vida.

A partir do momento em que o professor reconhece essas marcas sociais em seus alunos, pode desenvolver um trabalho para que o discente possa ter familiaridade entre a teoria aplicada ao seu contexto social, percebendo sua importância tanto na geração de riquezas, como na manutenção da estrutura de classes do Estado.

CATEGORIA II: Mecanismos que proporcionam a autonomia do aluno.

Considerando as especificidades dos alunos da EJA, quais mecanismos que podem ser utilizados para a superação de suas dificuldades?

Com intervenções pedagógicas para recuperar a aprendizagem dos alunos, e fortalecendo os saberes necessários a promoção da autonomia discente e a transformação daquilo que for necessário (P1).

Justamente colocando-o como sujeito participativo, ele é quem irá da um significado ao seu aprendizado partindo do seu valorizar como pessoa que tem suas necessidades distintas e que está em um processo de constante formação (P2). 
Elaboração de projetos, atividades diferenciadas para que assim venha ajudar o aluno a vencer suas dificuldades (P5).

As respostas dos professores denotam a ênfase em proporcionar o incentivo à autonomia do aluno, considerando, também, suas especificidades. Nessa perspectiva, recorremos ao pensamento de Freire (2013, p. 105):

Ninguém é sujeito da autonomia de ninguém. Por outro lado, ninguém amadurece de repente, aos vinte e cinco anos. A gente vai amadurecendo todo dia, ou não. A autonomia, enquanto amadurecimento do ser para si, é processo, é vir a ser. Não ocorre em data marcada. É neste sentido que uma pedagogia da autonomia tem de estar centrada em experiências estimuladoras da decisão e da responsabilidade, vale dizer, em experiências respeitosas da liberdade.

Tendo em vista a reflexão de Freire (2013), percebemos que o favorecimento ao protagonismo do aluno pode suscitar a formação de um sujeito que perceba sua responsabilidade no processo de aprendizagem, podendo agir e participar de forma mais ativa nas atividades em sala de aula. Isso pode favorecer a superação de dificuldades que dependam, em maior medida, do próprio aluno, como a concentração em determinada atividade e a reflexão na busca pelo entendimento de um dado fenômeno discutido em sala ou fora dela.

Nessa linha de reflexão, conforme o Parecer 11/2000,

Muitos estudantes da EJA, face a seus filhos e amigos, possuem de si uma imagem pouco positiva relativamente a suas experiências ou até mesmo negativa no que se refere à escolarização. Isto os torna inibidos em determinados assuntos (BRASIL, 2000, p. 63).

Consideramos, então, que as respostas dos professores participantes estão em concordância com a norma, na medida em que percebem as dificuldades de seus alunos e a necessidade de intervenções pedagógicas que os coloquem como sujeitos de seu aprendizado, promovendo a autoconfiança e a autonomia. Essa atitude docente corrobora com o 
pensamento de Freire (2013, p. 47): "ensinar não é transferir conhecimento, mas criar possibilidades para a sua própria produção ou a sua construção".

Dessa forma, uma condução docente que estimule a reflexão dos alunos sobre seu aprendizado possibilita a formação de um cidadão autônomo, no sentido de buscar respostas para suas dificuldades; além disso, estimula a constituição do sujeito que participa ativamente nas questões sociais, posicionando-se frente aos percalços que surgem em sua vida cotidiana.

\section{Os relatos dos alunos}

Quanto ao segundo momento, foi criada uma categoria a priori para o questionamento feito aos alunos e, com base nos critérios de similaridade e frequência das respostas, foram criadas subcategorias a posteriori, conforme o exposto na Figura 2:

Quadro 2 - Segundo momento: Quadro da categoria e subcategorias criadas em consonância com os objetivos da pesquisa e de acordo com a similaridade das respostas dos alunos

\begin{tabular}{|c|c|l|}
\hline CATEGORIA & \multicolumn{2}{|c|}{ SUBCATEGORIAS } \\
\hline Criada a priori & \multicolumn{2}{|c|}{ Criadas a posteriori } \\
\hline Participação ativa nas questões sociais & Subcategoria I & $\begin{array}{l}\text { Participação que } \\
\text { envolve a } \\
\text { materialização de } \\
\text { direitos }\end{array}$ \\
\cline { 2 - 3 } & Subcategoria II & $\begin{array}{l}\text { Participação que } \\
\text { envolve reinvindicações }\end{array}$ \\
\hline
\end{tabular}

Fonte: Elaborado pelo pesquisador, 2019.

CATEGORIA - Participação ativa nas questões sociais.

Considerando os alunos da EJA como cidadãos de direito, como sua formação escolar contribui para a participação ativa nas questões sociais?

Subcategoria I - Participação que envolve a materialização de direitos. 
Eu entendo que a educação pode me ajudar em muitos lugares. Ex: em creche, defensoria pública, ministério do trabalho (A2).

Posso fazer valer meus direito de cidadão como exemplo: Direito a concurso público a participar de palestra porque estou praticando mais minha leitura (A3).

Eu tenho consciência dos meus direitos, meus direitos de escola, da saúde, de creche pro meus filhos de transporte, de ir e vim (A4).

A educação que estou aprendendo na escola é para estar por dentro de tudo que acontece no nosso Brasil, sobre nosso município, nos nossos bairros e ruas e nossos direitos e deveres e dos nossos governantes (A18).

[...] eu busco me instruir para me tornar um cidadão participativo (A23).

[...] contribui bastante, para mim para entender melhor sobre o que ocorre na minha cidade no meu bairro, dando conhecimento para poder cobrar melhorias para todos (A24).

Os participantes destacam em seus argumentos que sua formação escolar ajuda em questões relacionadas ao conhecimento de direitos e como dispor dessas garantias. Essas falas nos levam à compreensão de que essa modalidade, sendo constituída por sujeitos que são afetados cotidianamente por questões que envolvem direitos e garantias, deve, por força da demanda de sua clientela, possibilitar a formação de cidadãos conscientes da realidade em que vivem, comprometidos com práticas sociais que promovam o bem comum.

A respeito da formação de consciência, Freire (1987, p. 08) explica que:

[...] ninguém se conscientiza separadamente dos demais. A consciência se constitui como consciência do mundo. Se cada consciência tivesse $O$ seu mundo, as consciências se desencontrariam em mundos diferentes e separados - seriam nômadas incomunicáveis. As consciências não se encontram no vazio de si mesmas, pois a consciência é sempre, radicalmente, consciência do mundo.

Freire (1987) reflete acerca da interferência que o meio exerce sobre o que pensamos e sobre a forma como lidamos com nossas reflexões. Portanto, precisamos desenvolver trabalhos educativos que promovam a 
reflexão sobre a realidade cotidianamente vivida pelos alunos da EJA, o que poderá influenciar para que esses sujeitos se percebam como cidadãos que possuem direitos.

No que se refere à compreensão da cidadania, concordamos com o seguinte pensamento de Capucho $(2012$, p. 30):

Nesse entendimento, a cidadania é sinônimo de autonomia individual, considerando o indivíduo sujeito autônomo, ou seja, cidadão(ã) cada vez menos dependente do Estado e se efetiva no regime democrático liberal, compreendido enquanto regime da lei e da ordem para a garantia das liberdades individuais.

O conhecimento é o primeiro passo para a materialização das garantias legais e humanas. Olhando efetivamente para a realidade dos cidadãos que compõem nosso país, entendemos que estes estão sob os ordenamentos jurídico, político e econômico que formam o Estado brasileiro. Portanto, a EJA não pode se abster de considerar as bases de formação da nação como pressupostos de um trabalho pedagógico voltado para o fortalecimento da cidadania.

Subcategoria II - Participação que envolve reinvindicações.

[...] a sociedade merece melhorar os ônibus, a crise econômica (A5).

Hoje em dia a cidade tá com muitos problemas falta de ônibus, questão de saúde de segurança e a educação ajuda na questão (A6).

Ter segurança para aluno à noite, transporte [...] (A7).

A nossa educação de hoje tem que melhorar mais pra gente participar da política, economia e da melhoria da nossa cidade (A16).

Sim nosso país tem que melhorar, porque o governo não se importa com a população, nos ajudar para interagirmos no convívio social do nosso pais (A19).

Nas respostas destacadas, verificamos demandas que envolvem problemas sociais. A ênfase se projeta na cobrança por direitos básicos, tais como: melhorar o sistema de saúde, promover a segurança, qualificar a 
educação e proporcionar melhor sistema de transporte coletivo. O posicionamento dos alunos participantes, direcionado às reivindicações, demonstra que esses sujeitos reconhecem a necessidade de discutir os problemas da sociedade.

A esse respeito, nos apoiamos no pensamento de Freire (1967, p. 11), que nos explica que:

Conscientizar não significa, de nenhum modo, ideologizar ou propor palavras de ordem. Se a conscientização abre caminho à expressão das insatisfações sociais é porque estas são componentes reais de uma situação de opressão.

Freire (1967) esclarece que, para que haja mobilização no sentido de reivindicações, é prerrogativa a existência de um dado problema que esteja interferindo, de alguma forma, no modo de vida. O autor ressalta, ainda, a necessidade de distanciar as concepções ideológicas, no sentido particular de uma dada forma de enxergar o mundo, das ações sociais e políticas que visam o bem coletivo.

O pensamento de Freire (1967) corrobora com o princípio de uma cidadania ativa. Segundo as palavras de Capucho (2012, p. 11), "Essa cidadania é entendida como a concretização dos diretos assegurados, o exercício para a garantia de novos direitos, reinvindicações e reclamação de direitos violados".

Estimular 0 interesse dos alunos da EJA, a partir das problemáticas sociais pelas quais esses sujeitos são afetados, propor trabalhos pedagógicos que reflitam essa realidade buscando extrair possibilidades para a resolução desses problemas. Isso poderá proporcionar melhor qualidade na formação escolar, na medida em que possibilita benefícios tanto para o aluno na busca por seus interesses e na resolução de suas dificuldades, como para sua comunidade que, ao invés de mero indivíduo espectador das mazelas sociais, terá um cidadão atuante pela melhoria do bem comum. 


\section{CONSIDERAÇÕES FINAIS}

Finalizando o presente estudo, é preciso que seja relembrado o objetivo proposto no início da pesquisa, qual seja: analisar como a formação dos alunos da EJA pode contribuir para a participação ativa nas questões sociais. Para o desdobramento desse objetivo geral, trabalhamos com os objetivos específicos descritos a seguir.

Quanto ao primeiro objetivo, acerca dos requisitos que o professor leva em consideração para o desenvolvimento do seu trabalho em sala de aula, tendo em vista a superação das dificuldades e necessidades dos alunos da EJA, foi possível averiguarmos que há uma valorização dos conhecimentos prévios dos alunos por parte dos docentes, denotando que o aluno está no centro do processo educativo. Nesse contexto, as práticas de ensino requerem olhar que parta do contexto sociocultural real dos alunos e, assim, partir dos saberes já adquiridos para a construção de novos conhecimentos sistematizados.

Com relação ao segundo objetivo, que consistiu em verificar se os alunos da EJA percebem sua formação escolar como um mecanismo de participação ativa nas questões sociais, são evidenciados elementos relacionados à materialização de direitos e reivindicações. É possível verificarmos que nos apontamentos dos participantes existe a preocupação com tudo o que acontece na sociedade, pois esses estudantes são afetados cotidianamente por decisões políticas e econômicas. O conhecimento formal poderá proporcionar aos alunos da EJA a participação ativa nas situações que envolvam seus direitos e garantias legais básicas, na medida em que promova formação que reflita a realidade social dos alunos e proporcione condições para que eles se tornem cidadãos reflexivos e sujeitos participativos.

Nesse contexto, em resposta à questão norteadora desta pesquisa, concluímos que é necessário que a formação dos alunos da EJA se efetive com a problematização dos conteúdos, alinhada à realidade sociocultural real dos alunos e com a melhoria das condições materiais de trabalho nessa modalidade de ensino. 
Estes são alguns apontamentos que servem como indicadores para ações que possam contribuir para a qualidade do ensino e aprendizagem naEJA.

\section{REFERÊNCIAS}

ARROYO, M. G. A Educação básica e o Movimento Social do Campo. In: ARROYO, M. G.; CALDART, R. S.; MOLINA, M. C. (Orgs.). Por uma Educação do Campo. Petrópolis: Vozes, 2011.

BARDIN, L. Análise de conteúdo. São Paulo: Edições 70, 2016.

BOGDAN, R. C.; BIKLEN, S. K. Investigação Qualitativa em Educação: uma introdução à teoria e aos métodos. Trad. Maria João Alvarez e Sara Bahia dos Santos. Portugal: Porto Editora, 1994.

BRANDÃO, C. R. Algumas ideias para pensar uma educação centrada na pessoa e destinada a se estender por toda a sua vida. In: Ministério da Educação. Secretaria de Educação Continuada, Alfabetização, Diversidade e Inclusão. Coletânea de textos CONFINTEA Brasil+6: tema central e oficinas temáticas. Brasília: MEC, 2016.

BRASIL. Parecer 11/2000 - Diretrizes Curriculares Nacionais para a Educação de Jovens e Adultos. 2000.2 Disponível em: <http://portal.mec.gov.br/cne/arquivos/ pdf/PCB11_2000.pdf>. Acesso em: 21 mar 2018.

BRASIL. Secretaria de Direitos Humanos da Presidência da República. Caderno Educação em Direitos Humanos: Diretrizes Nacionais. Brasília: Coordenação Geral, 2013.

CAPUCHO, V. Educação de jovens e adultos: prática pedagógica e fortalecimento da cidadania. São Paulo: Cortez, 2012.

DI PIERRO, M. C.; JOIA, O.; RIBEIRO, V. M. Visões da Educação de Jovens e Adultos no Brasil. Cadernos Cedes, ano XXI, nº. 55, 2001.

FREIRE, P. Educação como prática da liberdade. Rio de Janeiro: Paz e Terra, 1967.

FREIRE, P. Pedagogia do oprimido. Rio de Janeiro: Paz e Terra, 1987.

FREIRE, P. Conscientização: teoria e prática da libertação. São Paulo: Centauro, 2001. 
FREIRE, P. Educação de adultos: algumas reflexões. In: GADOTTI, M.; ROMÃO, J. E. (Orgs.). Educação de jovens e adultos: teoria, prática e proposta. $12^{a}$ ed. São Paulo: Cortez, 2011.

FREIRE, P. Pedagogia da autonomia: saberes necessários à prática educativa. São Paulo: Paz e Terra, 2013.

GADOTTI, M. Educação de jovens e adultos: correntes e tendências. In: GADOTTI, M.; ROMÃO, J. E. (Org.). Educação de jovens e adultos: teoria, prática e proposta. 12 ed. São Paulo: Cortez, 2011.

GADOTTI, M. Educação de adultos como direito humano. EJA em debate, ano 2, n². Florianópolis, 2013.

GIL. A. C. Métodos e técnicas de pesquisa social. 6 ed. São Paulo: Atlas, 2008.

JEFFREY D. C. et al. A Legislação Educacional e o conceito de qualidade na Educação de Jovens e Adultos: princípios e orientações. Revista Exitus, v. 03 n. 02, Jul/dez, 2013.

RUMMERT, S. M. Formação continuada dos educadores de jovens e adultos: Desafios e perspectivas. In: SOARES, L. (Org.). Formação de educadores de jovens e adultos. Belo Horizonte: Autêntica, SECAD/MEC/UNESCO, 2006.

UNESCO. Declaração Universal dos Direitos Humanos. Brasília: UNESCO, 1998.

Recebido em: 31 de agosto de 2020

Aprovado em: 26 de outubro de 2020

Publicado em: 16 de novembro de 2020 